\title{
Assessment of Self-Care Activities Using Diabetes Self- Management Questionnaire (DSMQ) amongst Diabetes Patients Attending a Rural Health Training Centre in Lucknow
}

\author{
Mohammad Suhail Khan¹, Syed Esam Mahmood², Ausaf Ahmad³, Anas Ahmad Khan, Islam Arfin ${ }^{5}$ \\ 1,3,4, 5 Department of Community Medicine, Integral Institute of Medical Sciences and Research, \\ Integral University Lucknow, Uttar Pradesh, India. ${ }^{2}$ Department of Family \& Community Medicine, \\ College of Medicine, King Khalid University, Abha, Saudi Arabia.
}

\section{ABSTRACT}

\section{BACKGROUND}

Hyperglycaemia is the main cause for diabetes related complications. Though a number of factors add to the blood glucose, it is broadly known that proper selfmanagement activities reduce the risk in diabetic patients. This study was conducted to assess the self-care activities and their adherence amongst the diabetic patients attending the RHTC, IIMSR Lucknow.

\section{METHODS}

This cross-sectional study involved 92 previously diagnosed diabetic patients attending the outpatient department of rural health training centre, Integral Institute of Medical Sciences and Research, Lucknow, from December 2017 to August 2018. Data was collected by personal interviews using diabetes self-management questionnaire (DSMQ). SPSS software version 16.0 was used for data analysis.

\section{RESULTS}

All patients were aged between 40 to 65 years and males were higher in proportion (56.0\%). About $96.3 \%$ subjects took diabetes medication as prescribed and $88.9 \%$ subjects recorded their blood sugar levels regularly. Nearly $77.8 \%$ did consistent exercise to accomplish optimal blood sugar stages \& 96.3 percent took the dietary advice given by investigator. About two-third patients avoided physical activity although they knew that it would improve their diabetes goal. About one third patients forgot or skipped their diabetes medication. The subscales of health-care use showed negative average intra class correlation. Mean score of subscale glucose management was maximum as compared to other subscales.

\section{CONCLUSIONS}

This study provides evidence that the DSMQ enables an efficient assessment of selfcare activities and their adherence among diabetes patients. Adherence to the treatment of diabetes and lifestyle modifications is the need of the hour.

\section{KEY WORDS}

DSMQ, Diabetes, Self-Care Activities, Cross-Sectional, Intra Class Correlation
Corresponding Author: Syed Esam Mahmood, Department of Family \& Community Medicine, College of Medicine, King Khalid University, Abha, Saudi Arabia. E-mail:semahmood@gmail.com

DOI: $10.14260 /$ jemds/2021/279

How to Cite This Article:

Khan MS, Mahmood SE, Ahmad A, et al. Assessment of self-care activities using diabetes self-management questionnaire (DSMQ) amongst diabetes patients attending a rural health training centre in Lucknow. J Evolution Med Dent Sci 2021;10(18):1324-1328, 10.14260/jemds/2021/279

Submission 21-08-2020,

Peer Review 23-01-2021,

Acceptance 30-01-2021,

Published 03-05-2021.

Copyright (C) 2021 Mohammad Suhail Khan et al. This is an open access article distributed under Creative Commons Attribution License [Attribution 4.0 International (CC BY 4.0)] 


\section{BACKGROUND}

Type two diabetes mellitus (T2DM) is a major cause of mortality, morbidity and increasing healthcare cost worldwide. ${ }^{1}$ There is a rise in broad range of manage and conventional medicine suggested at private and public organizations to casual private, and another standard care suppliers. ${ }^{2,3}$ India is projected to $2^{\text {nd }}$ highest frequency of patients of DM worldwide. This may be attributed to its urbanization, economic growth, and nutritional change. Indians have a tendency to develop and raise insulin resistance, higher abdominal adiposity (greater waist circumference in spite of lower body mass index), greater prevalence of impaired glucose tolerance, adding to a higher risk of growing disease at a comparatively younger age. They turn into obese and change to T2DM with usual weight; consequently, BMI cut-off for over-weight \& obesity is retain low in India. Policies for the disease are to be more emphasised at the community level. The unusual characteristic of diabetes as a non-communicable and chronic illness with life frightening effects ${ }^{4,5}$ and several modifiable and nonmodifiable risk factors ${ }^{6}$ has upheld its way to comprise lots of daily self-management by subjects further than the medical management. ${ }^{7}$ Diabetes self-management includes many important points: being physically active, proper eating, keep tracking of sugar level in blood, manageable with suggestion, fine problem explaining abilities, proper coping abilities and risk-management. ${ }^{8}$ Presented manners having positively associated with good glycaemic control, decrease of problems and perfection in quality of better life. ${ }^{8}$ Many instruments have been intended to measure patients' bond.7,9-13 Largely practiced inquiry form to measure diabetes self-management and routine adherence of SDSCA established by Toobert et al. ${ }^{7}$ Current assessments have not acknowledged its coherent and significant relationships with $\mathrm{HbA1c},{ }^{12}$ the main determination of glycaemic control.14 Nevertheless, comparatively DSMQ was described to display improved internal uniformity and validity ${ }^{15,16}$ It is a comparatively psychometric tool to observe diabetes self-manage behaviour. This tool may be of important for scientific studies investigating glycaemic control, relative to patients' diabetes self-management activities and also for practitioners looking for measure their subjects self-manage to classify activities for the development. Though, DSMQ to similar other valuation instruments basically assesses self-describe attachment to self-manage activities, hereafter the presentation of any instrument might vary person to person, health care facilities and varied social stimuli.16,17 Indications suggest that patients, who are informed about DM self-care, have good long term glycaemic control. Moreover, some studies have shown that disadvantaged disease awareness and uncooperative attitudes towards self-care practices among diabetic patients and few of the significant variables influencing the development of diabetes and its disablements, which are mainly preventable through knowledge and participation of the patient. Therefore, it is important to warrant that patient's knowledge, attitudes and practices about diabetes self-care are satisfactory. This study was conducted to assess the self-care behaviours by using a structured DSMQ-16 questionnaire among type 2 diabetes Mellitus patients attending the RHTC, IIMSR, Integral University Lucknow, Uttar Pradesh, India.

\section{METHODS}

This cross-sectional study was undertaken to observe the adherence to self-care management among 92 diabetes adults receiving care at the outpatient department of rural health training centre, Department of Community Medicine, Integral Institute of Medical Sciences and Research, Lucknow, from December 2017 to August 2018. Data collection was implemented by using a standardised questionnaire-diabetes self-care management (DSMQ-16) in the local language. ${ }^{12}$ Standard forward-backward translation was used to translate the DSMQ into Hindi language.

Prior approval from the institutional ethical committee was obtained.

\section{Measures}

The DSMQ-16 is an appropriate validated and generally used 16-item self-report scale for the measurement of type 2 diabetes, self-management of diabetes is a exponent of glycaemic control. ${ }^{15}$ The items are in four subscales: 'Dietary Control' (DC), 'Glucose Management' (GM), 'Physical Activity' (PA), and 'HealthCare Use' (HU); and described on a Likert Scale, scaling from 0 (does not apply) to 3 (very much applies) to originate a summed score for a 'Sum Scale' (SS). Sum of score and also valuation. According to their contents, the subscales were marked as 'Dietary Control' (items 2, 5, 9, 13), 'Glucose Management' (items 1, 4, 6, 10, 12), item numbers belongs to physical activity are 8,11 and 15 , and item numbers belongs to health care use are 3, 7 and 14. Overall rating for self-care is item sixteen and also added in sum scale' only. ${ }^{12}$ Data was collected by the principal investigator himself. The interviews were conducted in simple Hindi language, which is understood by the rural Indian population.

\section{Statistical Analysis}

Microsoft was used for data entry and Statistical Package for the Social Sciences (SPSS) 16.0 version was used for statistical analysis. Appropriate test statistic, average intraclass correlation coefficient, Kruskal-Wallis test for significance between medians were used for analysis of results. Statistical significance was taken as $\mathrm{P}$-value $<0.05$.

\section{RESULTS}

\begin{tabular}{|cccc|}
\hline \multicolumn{4}{c}{ Gender } \\
Age Group & Male & Female & Total \\
$\leq 40$ & $0(0.0 \%)$ & $3(7.0 \%)$ & $3(3.3)$ \\
$41-50$ & $27(55.1 \%)$ & $11(25.6 \%)$ & $38(41.3)$ \\
$51-60$ & $10(20.4 \%)$ & $21(48.8 \%)$ & $31(33.7)$ \\
$\geq 61$ & $12(24.5 \%)$ & $8(18.6 \%)$ & $20(21.7)$ \\
\hline \multicolumn{4}{|l}{ Table 1. Distribution of Respondents with Regard to Age and Gender } \\
\hline \multicolumn{4}{l}{ P-value < 0.0003} \\
\hline
\end{tabular}

Table 1 depicts the distribution of age group of respondents according to their gender. All the patients were in the age group of 40 years to 65 years. Mean age of the patients was 53.37 years. Most of the respondents were in the age group of 41 - 50 years. 


\begin{tabular}{|c|c|c|c|c|}
\hline $\begin{array}{l}\text { Questions about Self-Care Activities } \\
\text { (Over the Last } 8 \text { Weeks) }\end{array}$ & $\begin{array}{l}\text { Applies to Me } \\
\text { Very Much (\%) }\end{array}$ & $\begin{array}{l}\text { Applies to Me to a } \\
\text { Considerable } \\
\text { Degree (\%) }\end{array}$ & $\begin{array}{l}\text { Applies to Me } \\
\text { to Some } \\
\text { Degree (\%) }\end{array}$ & $\begin{array}{c}\text { Does Not } \\
\text { Apply to } \mathrm{Me} \\
(\%)\end{array}$ \\
\hline $\begin{array}{l}\text { I check my blood sugar levels with care and attention. Blood sugar measurement is not required as a } \\
\text { part of my treatment. }\end{array}$ & $39(42.4)$ & $24(26.1)$ & $23(25.0)$ & $6(6.5)$ \\
\hline The food I choose to eat makes it easy to achieve optimal blood sugar levels & $30(32.6)$ & $42(45.7)$ & $14(15.2)$ & $6(6.5)$ \\
\hline I keep all doctors' appointments & $48(52.2)$ & $34(37.0)$ & $10(10.9)$ & $0(0.0)$ \\
\hline I take my diabetes prescription (e.g. insulin, tablets) as advised. & $68(73.9)$ & $17(18.5)$ & $3(3.3)$ & $4(4.3)$ \\
\hline Occasionally I eat lots of sweets or other foods rich in carbohydrates. & $16(17.4)$ & $17(18.5)$ & $46(50.0)$ & $13(14.1)$ \\
\hline I record my blood sugar levels regularly & $21(22.8)$ & $17(18.5)$ & $43(46.7)$ & $11(12.0)$ \\
\hline I tend to avoid diabetes-related doctors' appointments. & $10(10.9)$ & $17(18.5)$ & $22(23.9)$ & $43(46.7)$ \\
\hline I do regular physical activity to achieve optimal blood sugar levels. & $6(6.5)$ & $25(27.2)$ & $41(44.6)$ & $20(21.7)$ \\
\hline I strictly follow the dietary recommendations given by my doctor or diabetes specialist. & $27(29.3)$ & $23(25.0)$ & $39(42.4)$ & $3(3.3)$ \\
\hline I do not check my blood sugar levels & $17(18.5)$ & $26(28.3)$ & $31(33.7)$ & $18(19.6)$ \\
\hline I avoid physical activity, though it would get better. & $19(20.7)$ & $39(42.4)$ & $13(14.1)$ & $21(22.8)$ \\
\hline $\begin{array}{l}\text { I tend to forget to take or skip my diabetes medication (e. g. insulin, tablets). } \\
\text { Diabetes medication / insulin is not required as a part of my treatment. }\end{array}$ & $8(8.7)$ & $15(16.3)$ & $14(15.2)$ & 55 (59.8) \\
\hline Sometimes I have real 'food binges' & $0(0.0)$ & $30(32.6)$ & $30(32.6)$ & $32(34.8)$ \\
\hline Regarding my diabetes care, I should see my medical practitioner (s) more often. & $16(17.4)$ & $42(45.7)$ & $21(22.8)$ & $13(14.1)$ \\
\hline I tend to skip planned physical activity. & $22(23.9)$ & $21(22.8)$ & $20(21.7)$ & $29(31.5)$ \\
\hline My diabetes self-care is poor. & $0(0.0)$ & $35(38.0)$ & $39(42.4)$ & $18(19.6)$ \\
\hline
\end{tabular}

Minimum number of study subjects were in the age group of less than or equal to 40 years. Above table shows that $53.0 \%$ were male subjects and $47.0 \%$ were female subjects. Majority of female study subjects were in the age group of 51 - 60 years. Whereas males were predominantly in the age group of 41 50 years. There were significant differences between age group and gender. (Table 1 and Figure 1)

Table 2 illustrates that overall, $92.5 \%$ check their levels of blood sugar with proper attention. 93.5 percentage of study subjects selected their food to achieve optimal levels of blood sugar. Hundred percent subjects kept up all doctors' appointments recommended. $95.7 \%$ took diabetes medication as advised. About $88.0 \%$ subjects recorded their blood sugar levels regularly. $78.3 \%$ patient's did regular physical activity to achieve optimal levels of blood sugar and $96.7 \%$ study subjects followed their doctors advise strictly. $68.4 \%$ patients were avoiding physical activity whereas 40.2 $\%$ were following diabetes prescription (e.g., insulin, tablets). (Table 2).

Table 3 shows the subscale characteristics and average intraclass correlation. The average intra class correlation was higher at 0.256 indicating satisfactory homogeneity of the DSMQ questions and the confidence interval was - 0.028 to 0.476 at $95 \%$.

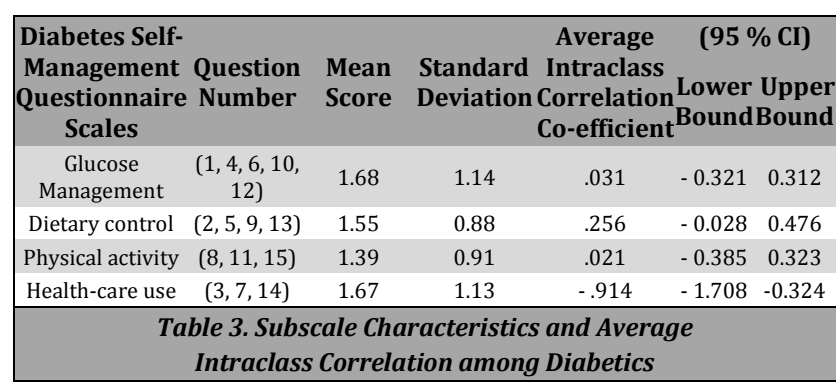

The subscales of health-care use showed negative average intra class correlation. Average intra class correlation coefficient is an index for the reliability of different questions collectively, in which question number $8,11,15$ of physical activity having lowest followed by $1,4,6,10,12$ of glucose management. Mean score of subscale glucose management was maximum as compared to other subscales. (Table 3)

Table 4 describes the significant differences between questions using Kruskal-Wallis test, in which rank column displays the details about the mean ranks for each categories of every subscale. In glucose management, mean rank of question four was highest, followed by question one and question 12 had lowest impact in it.

\begin{tabular}{|c|c|c|c|c|c|}
\hline $\begin{array}{c}\text { Diabetes Self- } \\
\text { Management } \\
\text { Questionnaire Scales }\end{array}$ & Questions / Statements & $\begin{array}{l}\text { Mean } \\
\text { Rank }\end{array}$ & $\begin{array}{c}\text { Chi } \\
\text { Square }\end{array}$ & $\begin{array}{l}\text { Degree of } \\
\text { Freedom }\end{array}$ & $\begin{array}{c}\text { P- } \\
\text { Value }\end{array}$ \\
\hline \multirow{5}{*}{ Glucose management } & I check my blood sugar levels with proper attention & 271.06 & \multirow{5}{*}{140.48} & \multirow{5}{*}{4} & \multirow{5}{*}{0.000} \\
\hline & I take my diabetes prescription (e. g. insulin, tablets) as advised & 338.51 & & & \\
\hline & I record my blood sugar levels regularly (or analyse the value chart with my blood glucose metre) & 211.82 & & & \\
\hline & $\begin{array}{l}\text { I do not check my blood sugar levels frequently enough as would be required for achieving good blood } \\
\text { glucose control }\end{array}$ & 204.21 & & & \\
\hline & I tend to forget to take or skip my diabetes prescription & 126.91 & & & \\
\hline \multirow{4}{*}{ Dietary control } & The food I choose to eat makes it easy to achieve optimal blood sugar levels & 237.50 & \multirow{4}{*}{63.12} & \multirow{4}{*}{3} & \multirow{4}{*}{0.000} \\
\hline & Occasionally I eat lots of sweets or other foods rich in carbohydrates & 165.38 & & & \\
\hline & I strictly follow the dietary recommendations given by my doctor or diabetes specialist & 208.65 & & & \\
\hline & Sometimes I have real 'food binges' (not triggered by hypoglycaemia) & 126.47 & & & \\
\hline \multirow{3}{*}{ Physical activity } & I do regular physical activity to achieve optimal blood sugar levels & 122.94 & \multirow{3}{*}{7.89} & \multirow{3}{*}{2} & \multirow{3}{*}{0.019} \\
\hline & I avoid physical activity, although it would improve my diabetes & 154.82 & & & \\
\hline & I tend to skip planned physical activity & 137.74 & & & \\
\hline \multirow{3}{*}{ Health-care use } & I keep all doctors' appointments advised & 191.63 & \multirow{3}{*}{83.76} & \multirow{3}{*}{2} & \multirow{3}{*}{0.000} \\
\hline & I tend to avoid diabetes-related doctors' appointments & 88.03 & & & \\
\hline & Regarding my diabetes care, I should see my medical practitioner (s) more often & 135.84 & & & \\
\hline \multicolumn{6}{|c|}{ Table 4. Significant Differences between Questions Using Kruskal-Wallis Test } \\
\hline
\end{tabular}


Highest mean rank of dietary control, physical activity and health-care use were question number 2, 11, and 3 respectively. Statistical test showed that there was a statistically significant difference in between diabetes selfmanagement questions. (Table 4)

\section{DISCUSSION}

The present study disclosed the information using a validated self-administered questionnaire to evaluate the self-care behaviours amongst diabetes patients of Lucknow. The approach of tool was helpful in identifying the problems regarding self-care activities. In present study, the patients were in the age group of 40 to 65 years. Few of them were in the age less than or equal to 40 years. Fifty-three percentages were males and $47.0 \%$ were female. Whereas males were predominantly in the age group of 41 - 50 years. Similar study included 103 participants had a mean and standard deviation age of 62.2 (11.3) years. Majority of them were males (26.2 \%). ${ }^{18}$ Elderly group were weak individuals usually suffering from multiple ailments and may have negotiated self-care activities. This observation was similar to studies done by Karampadmaat et al. and Shah et al. where majority of the patients were in the age group of 55 years. Study results showed majority of the patients with poor glycaemic control belonged to this age group. ${ }^{19}$ Moreover, Al Shayban (2017) comprised 30 eligible study subjects, 56 percent were aged above 60 years, 32 percent were aged between 41 and 60 years. 60 percent were women and 40 percent were men. ${ }^{20}$ In present study, $92.5 \%$ checked blood sugar levels with attention and care. $100 \%$ subjects retained all doctors' appointments recommended. $95.7 \%$ took diabetes medicine as advised. Patients who were not consistent in exercise to attain ideal blood sugar levels and strictly obeyed the dietary advice specified by the practitioners were $78.3 \%$ \& $96.7 \%$ respectively. Average intra class correlation was higher at 0.256 representing suitable homogeneity of the DSMQ questions and confidence interval was -0.028 to 0.476 at 95 $\%$. The subscales of health-care use showed negative average intra class correlation. Mean score of subscale glucose management was maximum as compared to other subscales. Babatunde and Onu (2018) estimated average inter-item correlation was high at 0.75 representing suitable similarity of the DSMQ items. ${ }^{21}$ The average items scores for the using the health-care subscale were minimum or equal to that of the original. In contrast Bukhsh et al. ${ }^{16}$ also reported that, this possibly is the poorer health set-up and health-seeking behavior. ${ }^{22}$ Multivariate analysis depicted that when measured together only the glucose \& dietary control subscales were significantly related with improved glycaemic control, although the health-care use and physical activity subscales were not. ${ }^{16}$ Mehravar et al. 2016 described greater score for glucose management and physical activity, which might be because of cultural and health care services amongst the countries. Probably alike results were detected in a study carried out in Iran, ${ }^{23}$ where greater scores on glucose management and dietary control subscales were described as linked to rest of the sub-scales of the DSMQ. ${ }^{16}$ In present study glucose management mean rank of question four was highest, followed by question 1 and question 12 had lowest impact in it. Furthermore, Bukhsh et al. in 2017 observed significant differences between DSMQ scores in different patient groups. ${ }^{16}$ Self-care behaviour experienced by diabetic patients nonetheless, also their information and attitudes that could control the characters were depicted. Diabetes self-care comprises a range of activities; self-care is multi-dimensional; it is important to assess each part separately rather than to aggregate scores across parts. Consequently, some aspects of diabetic self-care: 'dietary control', 'glucose management', 'physical activity' and 'health-care use' were measured in the present study using standard questionnaire. The findings of the present study have provided complete baseline evidence on diabetes self-care activities experienced by patients, based on which upcoming interventions will be prearranged. There are some boundaries of present study, primarily connected to background and composition of the sample composed at a diabetes referral centre as well as the study's cross-sectional design and valuation can ascend from the management of the instrument at the health centre, and patients were willing to give promising replies to questions that were offered to them in the inquiry form.

\section{CONCLUSIONS}

This study provides evidence that the DSMQ enables an efficient assessment of self-care behaviours among diabetes patients. Adherence to the treatment of diabetes and lifestyle modifications is the need of the hour. Regular imparting of health education, making the patients conscious about diabetes and encouraging self-care management during treatment will decrease the overall health issues in diabetic patients.

Data sharing statement provided by the authors is available with the full text of this article at jemds.com.

Financial or other competing interests: None.

Disclosure forms provided by the authors are available with the full text of this article at jemds.com.

\section{REFERENCES}

[1] Seuring T, Archangelidi O, Suhrcke M. The economic costs of type 2 diabetes: a global systematic review. Pharmacoeconomics 2015;33(8):811-31.

[2] Ogbera AO, Ekpebegh C. Diabetes mellitus in Nigeria: The past, present and future. World J Diabetes 2014;5(6):90511.

[3] Chinenye S, Ogbera AO. Socio-cultural aspects of diabetes mellitus in Nigeria. J Soc Health Diabetes 2013;1(1):1521.

[4] Unachukwu CN, Uchenna DI, Young E. Mortality among diabetes in patients in Port Harcourt Nigeria. African J Endocrinol Metabol 2008;7(1):1-4

[5] Unachukwu C, Babatunde S, Ihekwaba AE. Diabetes, hand and/or foot ulcers: a hospital-based cross-sectional study in Port Harcourt, Nigeria. Diabetes Res Clin Pract 2007;75(2):148-152.

[6] Danaei G, Finucane M, Lu Y, et al. National, regional and global trends in fasting plasma glucose and diabetes prevalence since 1980: systematic analysis of health 
examination surveys and epidemiological studies with 370 country-years and 2.7 million participants. Lancet 2011;378(9785):31-40.

[7] Toobert DJ, Hampson SE, Glasgow RE. The summary of diabetes self-care activities measure: results from 7 studies and a revised scale. Diabetes Care 2000;23(7):943-50.

[8] Shrivastava SR, Shrivastava PS, Ramasamy J. Role of selfcare in management of diabetes mellitus. J Diabetes Metab Disord 2013;12(1):14.

[9] Cerkoney KA, Hart LK. The relationship between the health belief model and compliance of persons with diabetes mellitus. Diabetes Care 1980;3(5):594-8.

[10] Brownlee-Duffeck M, Peterson L, Simonds JF, et al. The role of health beliefs in the regimen adherence and metabolic control of adolescents and adults with diabetes mellitus. J Consult Clinical Psychol 1987;55(2):139-44.

[11] Eigenmann CA, Colagiuri R, Skinner TC, et al. Are current psychometric tools suitable for measuring outcomes of diabetes education? Diabet Med 2009;26(4):425-36.

[12] Schmitt A, Gahr A, Hermanns N, et al. The Diabetes SelfManagement Questionnaire (DSMQ): development and evaluation of an instrument to assess diabetes self-care activities associated with glycemic control. Health Qual Life Outcomes 2013;11:138-51.

[13] Lu Y, Xu J, Zhao W, et al. Measuring self-care in persons with type-2 diabetes a systematic review. Eval Health Prof 2016;39(2):131-84.

[14] Sacks DB, Arnold M, Bakris GL, et al. Guidelines and recommendations for laboratory analysis in the diagnosis and management of diabetes mellitus. Clin Chem 2011;57(6):e1-e47.

[15] Schmitt A, Reimer A, Hermanns N, et al. Assessing diabetes self-management with the Diabetes SelfManagement Questionnaire (DSMQ) can help analysebehavioural problems related to reduced glycaemic control. PLoS One 2016;11(3):e0150774.

[16] Bukhsh A, Lee SWH, Pusparajah P, et al. Psychometric properties of the Diabetes Self-Management Questionnaire (DSMQ) in Urdu. Health Qual Life Outcomes 2017;15:200-8.

[17] Ayele K, Tesfa B, Abebe L, et al. Self care behavior among patients with diabetes in harari, eastern ethiopia: the health belief model perspective. PLoS One 2012;7(4):e35515.

[18] Ang JY, Leo JS, George D, et al. Inadequate self-care behaviors among malaysian diabetic patients: the need for action by hospital pharmacists. J Pharm Pract Community Med 2018;4(2):51-4.

[19] Kakade AA, Mohanty IR, Rai S. Assessment of knowledge, attitude and self-care activities among type- 2 diabetic patients attending a tertiary care teaching hospital. Int J Basic Clinharmacol 2016;5:2458-62.

[20] Al Shayban DM. Diabetes Self-Management Questionnaire (DSMQ) to assess diabetes self-care activities for diabetes patients in king fahad university hospital-Saudiarabia. Value In Health 2017;20:399-811.

[21] Babatunde S, Onu R. Psychometric performance of the Diabetes Self-Management Questionnaire (DSMQ) among individuals attending a referral hospital in Port Harcourt, Nigeria. SM J Public Health Epidemiol 2018;4(1):1047.

[22] Akinniyi AA, Olamide 00. Missed medical appointment among hypertensive and diabetic outpatients in a tertiary healthcare facility in Ibadan, Nigeria. Trop J Pharm Res 2017;16(6):1417-24.

[23] Mehravar F, Mansournia MA, Holakouie-Naieni K, et al. Associations between diabetes self-management and microvascular complications in patients with type 2 diabetes. Epidemiol Health 2016;38;e2016004. 